\title{
The Role of Radio in Fostering Economic Empowerment of Rural Women in Bogije Ibeju-Lekki, Lagos
}

\author{
Ubong-Abasi Usoroh \\ School of Media and Communication, Pan-Atlantic University, Lagos, Nigeria
}

\begin{abstract}
This research sheds light on radio's role in advancing women economic empowerment in Bogije - a rural semiurban settlement in the outskirt of Lagos Island. Deploying qualitative approaches to research often known as interviews, the research concludes that although observable efforts have been invested in spotlighting most issues around female empowerment - precisely economic empowerment through media formats such as drama, sensitization and orientation on government aids and skills acquisition programmes, talk shows, interviews with government personnels, coverage of NGO activities on this issue, primarily, much is yet to be done about radio's reach and other deep rooted issues which limits radio's ability to properly deliver on its key responsibilities. The paper arrives at a position which presents a need to deal with the root causes limiting radio's ability to function properly on this subject of focus. It further sheds light on the need for women's economic empowerment to be taken more seriously as is done on health empowerment. It stretches across a need to monitor how women are discussed on air as they are sometimes presented as needy, helpless and desperate humans in need of rescue and empowerment which further dampens feminist goals and aims of proper female representation and empowerment. Ultimately, the paper acknowledges radio's efforts at playing a vital role in female's economic empowerment in Bogije while it calls for loopholes to be sealed and more efforts invested as much is yet to be done in achieving women's economic empowerment in Bogije, Ibeju Lekki, Lagos.
\end{abstract}

Keyword: Female empowerment, women economic empowerment, women and media, radio and female empowerment, Bogije

DOI: $10.7176 / \mathrm{JRDM} / 75-06$

Publication date:May $31^{\text {st }} 2021$

\section{Introduction and Background of Study}

Development stems from the zeal to grow or advance into something. Underpinning Development is the concept of empowerment which is ideally equipping self or the subject in need of growth with the skills or technical know-how, tools, finances and every other requirement needed for advancement. From time immemorial, one would have observed through engagement with historical sites, photographs and stories that society advanced through time and remains dynamic with reference to all sectors and ramifications of society. Observably, humans experience dynamism or turn in events in their pursuit of goals and interests as change remains the only constant thing. They find themselves in the cycle of change while manufacturing, recycling and altering artificial and natural changes around their environments and in the society. Underpinning the advancements are empowered elements determined to change. In essence, for change towards advancements to occur; one needs to be empowered - that is to possess or be equipped with the capacity to properly change or advance things around.

Generally, and over the years, studies have shown that society and mass media have often poorly portrayed women as dependent, weak and unable to produce value within different spheres of society (Narayana \& Ahamad, 2016). Along these stereotypical lines, the image of the female gender has been distorted and negatively perceived overtime. As societies progressed into an era of gender sensitivity, gender equality and general enlightenment on different issues, NGOs, governments and Scholars began to call for a reconstruction or shift away from observably traditional and practiced gender paradigms in society. While this trend of enlightenment has been theoretically received and practised in some societal quarters, other sectors may be presumed to be catching up with the trend on advancements in gender discusses and practices.

Along this lane of thought, there is an understanding that although mass media often project women under the scope of victimized, objectified, oppressed, ignored, helpless, dependent and vulnerable to poverty - mass media is as well responsible for the elimination or eradication of various stereotypical images and discrimination against women in the world today (Nirmala, 2015). The same perspective has been maintained by scholars who have researched into media's portrayal of women across societies and within varying contexts. Over decades, the perspectives and perceptions have been the obtainable position about women as viewed from media's lens, social lenses and within research results available within the academia. Hence, theories such as the feminist theory and other theories proposing liberation, empowerment and equality for the female gender.

From the accounts espoused, one may have observed a trend situated on the basis that this study arises from the backdrop of inequalities aimed at women and the new trend towards gender equality and proper representation and empowerment of women in different facets of society and through media's frame. From a perspective of information empowerment, this paper is concerned with the role radio plays in supporting 
economic empowerment of rural women in Ibeju Lekki, Lagos. This paper intends to assess the disconnect between radio and a community in Lekki Ibeju in a bid to identify key problems limiting radio's ability to assist in the economic empowerment of rural women in Ibeju Lekki and to proffer solutions in line with growth goals of society.

\section{Definition and Brief Discussion on Variables}

From 1933, the era of the British colonial government where the Radio Distribution System (RDS) was established under the department of Post and Telegraph in Lagos through to the era where the first private radio station (Ray-Power FM) was established in 1994 (Elutidoye, 2017), - up until this moment, studies have shown that Radio which is an electronic media that receives audio messages from a broadcast station usually on a frequency on the spectrum remains the most wide spread and accessible medium of information readily available to Nigerians (Asemah, 2011). Due to its cheap and portable nature, radio had permeated fabrics of society, through to rural areas and has been an asset used by government, corporations and individuals for society's development and to motivate shifts away from harmful practices (Asemah, 2011, p343). Somolu, (2013) solidifies the claim that radio maintains a central position as the primary source of information to majority of Nigerians. Radio as a form of mass media practice and as a social institution has served society and indeed Nigeria through landmark dates and times even up until Nigeria's independence in 1960. Being one of the most pervasive means of communication, radio has been used to communicate rapidly to mass audience and remains a medium of choice for government, corporations and individuals who aim to access the attention of the masses (Asemah, 2011). Key to its existence are responsibilities and social expectations required of radio by society expectations along the lines of economic empowerment of women through broadcast of vital information to specific citizens and groups existent in certain remote or rural areas.

At this juncture, it is safe to submit that radio in Nigeria is powerful, influential and pervasive as a medium of mass communication. With reference to this observation, media professionals owe society a responsibility to be mature, neutral, morally/ethically balanced in the deployment of radio for communication and development of society.

On defining economic empowerment, Gupta (2018) defines economic empowerment for women as the freedom or leverage accorded a woman as a human person to make financial and economic decisions. Along that lane, Economic empowerment for women has been placed in the context of proper monetary remuneration for every woman's effort, financial independence and poverty eradication through skills acquisition and entrepreneurship for women as the future of modern society (The Tide, 2016). Furthermore, OEDC (2018) contextualizes economic empowerment as the capacity of humans to engage with, contribute to and be properly compensated for participating in growth and value creation processes usually through processes that acknowledges the importance of their efforts; respects the dignity of their person/ labour and fosters an egalitarian distribution of growth benefits. The focus here covers the understanding that economic empowerment includes access to information, opportunities and resources e.g. jobs, properties and other assets, skills development, market information, etc. (OEDC, 2018). While OEDC (2018) maintains the perspective that women's economic empowerment must be primarily supported by laws and policies, practical procedures to enforce these policies and laws as well as a long term and sustainable approach to ensuring that beneficiaries and donors continuously develop, this paper's primary economic empowerment focus will be on skills development, information and job opportunities.

\section{Statement of Problem}

While radio may be seemingly playing its part in economically empowering Lekki - Ibeju women through information provision, job and skills development, less positive impact has been observed in Lekki-Ibeju. This major disconnect is the problem and this paper intends to discover the cause(s) of this disconnect from sampled radio's angle and from women in Ibeju-Lekki's perspective. In diagnosing the problem, it hypothesizes that reach, quality of content and audience interest may be the key causes of this observed disconnect. Hence, the need to tackle the disconnect for radio to properly function in empowering rural women in Ibeju-Lekki. This disconnect is consequential to society's advancement and different stakeholders because a continuous decline of this disconnect in economic empowerment of rural women in Ibeju Lekki will negatively impact all ramifications of rural women's wellbeing from inability to avail self of opportunities provided by government and corporations to improve the living standards of women to worsening health conditions caused by inability to access support caused by lack of information. Furthermore, rural women in Ibeju Lekki may be unable to feed or to attain selfactualization and find satisfaction existing as an asset to society and the country's labour force as a result of this disconnect. Accordingly, if this disconnect continues, radio would have also failed in further informing women and playing its crucial role in advancing society. This disconnect will further incur future costs for government as a continuous decline in the living standard of women in Ibeju Lekki will at some point imply government's intervention which will cost more as it will appear as an emergency. 


\section{Objectives of the Study}

1. Identify the specific methods radio deploys in economically empowering women in Bogije-Ibeju-Lekki.

2. To know specific radio programmes and content that impact women economically (skills acquisition information and economic information) in Ibeju-Lekki and how it can be buttressed.

3. To discover challenges or hindrances that may be preventing radio from empowering women in IbejuLekki as it relates to audience interest

4. To find out if selected radio stations are received and understood in Bogije - Ibeju-Lekki.

\section{Research Questions}

1. How is radio fostering economic empowerment for rural women in Bogije, Ibeju Lekki?

2. What broadcasted radio programmes aid in fostering economic empowerment for rural women in Bogije Ibeju-Lekki?

3. Could audience interest be hindering radio's effort aimed at fostering economic empowerment for rural women in Bogije Ibeju-Lekki?

4. Are sampled radio stations received and understood in Bogije- Ibeju- Lekki?

\section{Theoretical Framework Agenda Settings Theory}

In understanding the role of radio in fostering economic empowerment of rural women in Ibeju Lekki, the Agenda settings theory will be adopted as a lens to guide and explain the perspective of this paper. Propounded by Maxwell McCombs and Donald Shaw in 1972, the Agenda Settings theory expands upon the idea that mass media dictates the public agenda through selective projection and emphasis on certain issues while consecutively ignoring others - hence the postulation that mass media wields a great deal of influence in directly or indirectly influencing the masses to think about emphasized issues (Potter, 2014). An understanding of this theory stems from two connected positions. First, the premise that all individuals have come to know has been driven by mass media; secondly, awareness as an experience of mass media does not emphatically coerce us to think, rather it subtly conjures emotions, places emphasis on events and issues while suggestively spurring individuals to raise questions around aired issues powered by the human's inquisitive and curious nature (Asemah, 2011). It is at this phase that Mass Media captures its audience's interest while inducing thought through discussions and engagement with media content (Asemah, 2011). In essence, administering what to think about to its audience as opposed to dictating what to think (Wimmer \& Dominick, 2006)

In the context of this research, the Agenda settings theory explains the ideal role, responsibility as well as radio's insidious responsibility to society. In extension, the Agenda settings theory captures the effect radio can and has had on its audience (general and specific audiences). This further implies that the theory can function from another angle which is to help assess the ability of radio to properly execute one of its primary functions which is to set agenda either subtly or obviously and help in advancing society. Within the purview of this study, the Agenda settings theory will help the paper assess the types of agenda radio is setting to either help or worsen the case surrounding economic empowerment for rural women in Ibeju Lekki. From another angle, the impact of the agenda pushed by radio to rural women in Ibeju Lekki will be assessed to see if and how well the agenda of fostering economic empowerment for rural women in Ibeju Lekki is being received and acted upon or not received in any case.

\section{Empirical Literature Review}

Within varying contexts, Musubika (2008) in Uganda had researched into radio's role in empowering rural women, using interviews and focus group approaches to in-depthly question the operations of a case study being Mama FM (a radio station established to broadcast gender sensitive issues, informational and developmental programmes meant to help underprivileged and marginalized women in rural areas); Musubika (2008) concluded that although the station faced funding challenges, they were able to utilize available funds to promote the concerns of rural women and open them up to opportunities to participate in national and international programmes. In line with these strides, Mama Fm was able to educate women on key issues such as women's right against abuse and discrimination, broadcast a repertoire of informative programmes such as drama to entertain women and psychologically prepare them for the roles they play in society. Within similar programmes, helplines were strategically embedded within these programmes to aid women contact these helplines in times of distress. Also, an interactive approach was adopted by Mama Fm to ensure that women were able to interact with the radio station through calls (in the midst of any programme) to join in or make contributions to the conversation in focus.

The perspective differs slightly as it concerns the role of community radio in fostering empowerment for women in India. Nirmala (2015) in a research paper emphasized the observable roles of Community radio as giving a voice to the voiceless and to the minority groups within a certain jurisdiction. From examples cited 
within India, Community radio stations such as Namma Dhwani (Our Voices) and Sangham Radio were known to invite rural women to talk about issues bothering them and to broadcast and call for help from corporate organizations and government. Manndeshi Tarang radio owned by Mhaswad village community had more than often been known to encourage women to showcase their talent on air and had played a motivational role inspiring and encouraging women across the nooks and crannies of the village to utilize opportunities provided them by NGOs and government to economically develop self (Nirmala, 2015).

The perspective on media's approach to empowering women transcends various methods and has also been rooted within alternative media spheres. In this circle of concern, rural women who are often uneducated, uniformed and unable to speak up about dehumanizing treatments meted on them have often been encouraged by alternative media e.g. radio, newspaper, TV etc. to seek help using helplines provided on air (Devi, 2012). Being that alternative media will more than often focus on important issues ignored by the main stream media, Devi (2012) highlighted the perspective that alternative media embodied in radio often step in to highlight, rescue and guide rural women while sensitizing women on their intrinsic and extrinsic rights (Devi, 2012).

Furthermore, while examining the relationship between access and impact of radio for women's development, Somolu's (2013) paper touched on empirical qualitative data demonstrating the role of radio in empowering women. Somolu (2013) researched into avenues radio has contributed to observable socioeconomic changes in the lives of three groups of women - 1. Stay at home wives/mothers, 2. University and Polytechnic students 3.Self-employed business women. Using a focus group method to engage respondents, the research findings displayed an array of interesting revelations. As it relates to the focus of this paper, the findings unique to stay at home women emphasized the perspective that Lagos based stay at home women were primarily interested in health programmes focused on women and while they hated the fact that most programmes were often judgemental towards women who called in to complain about their health, programmes along the health pathways furnished women with vital information to self-medicate and manage stress or seek help where symptoms or illnesses required attention by medical professionals. Business women aged between 25-45 on the other end settled for programmes with emphasis on relationships, shopping and community. While they stressed that radio contents rarely focused on women, they pointed to the premise that radio programmes such as Oju Taye (Eyes, See the world) allowed them to complain to the government about issues and challenges they face; even Eku Oro Aje was also mentioned as an information program that provided women with information on the best goods and deals in the market and where to find them (Somolu, 2013).

Key findings in Somolu's (2013) research pointed to the perspective that radio remained a major source of information to women and although programmes targeted at them were scarce, they were able to properly utilize the ones at their disposal to advance their lives and empower themselves. Along that line, the paper had proposed that women be more involved (through phone calls) in shaping future programmes and radio's interest on issues focused on women (Somulu, 2013)

Akhter and Mashed (2014) researched into the perception of educated women as regards the role of media in empowering women. This research was conducted to aid the researcher propose better ways mass media could serve women in Pakistan. Using a questionnaire, they surveyed four hundred and ninety-nine (499) literate female respondents in Pakistan. Their findings revealed that familial issues unique to concerns of women were often discussed on mass media platforms - issues such as violence against women, rights and roles of women in society as well as the education of the girl child were also often discussed in mass media platforms but then, Programmes that could aid the professional and economic development of women, such as the educating women on wealth generation and creation, career choices, gender equality awareness were either avoided, weak or lacking. On a similar pedestal, Moghadam's (2007) paper delved in on the idea that mass media in India has been able to impact greatly on education of the girl child because against all cultural and religious norms and odds, they (mass media including radio) have been able to convince most rural dwellers to educate the girl child and grant them freedom to join India's work force.

Interestingly, while literatures analysed have shown that radio's focus on empowerment or development geared towards the female gender has primarily focused on health, family/household, rights, social and educational empowerment for women and the female gender in general, some key efforts and heavy thrusts have been observed in economic empowerment of within an African context.

\section{Research Methodology}

Evidently, to present a clear picture of radio's effort towards economic empowerment of rural women within Ibeju-Lekki Lagos, this study will be required to provide empirical evidence to demonstrate current mass media (radio) strides within instances and jurisdictions to aid a current understanding of radio's effort in fostering economic empowerment of rural women in Ibeju-Lekki. Accordingly, these strides would also highlight media's effort in rejuvenating/ positively changing or worsening society's perception of women. Secondarily, data and discussions detailing a perspective on radio's impact on women i.e. in economically empowering women in Ibeju Lekki will be assessed to aid this study achieve its aims and objectives. 
To achieve these aims the paper will be divided into two. First - A case study of four (4) radio stations based in Lagos will be assessed and evaluated on its effort towards economically empowering women in LekkiIbeju. A structured interview will be conducted on 4 administrative officers within 4 radio stations to understand and evaluate the strides of radio towards fostering economic empowerment of rural women in Ibeju Lekki and countering the negative tilt where observed. Secondly, the focus will be shifted towards assessing impacts on women of Bogije in Ibeju Lekki - with the aim to understand the underlying causes and threats surrounding the emerging disconnect between radio and its ability to properly empower Bogije women of Ibeju-Lekki.

In essence, the study will assess radio's role in fostering economic empowerment for rural women in IbejuLekki. Then using findings from the first approach, the second approach will attempt to assess the observed disconnect earlier outlined from the perspective of rural women at Ibeju Lekki.

\section{Sampling/ Respondent Selection}

Being that this research paper is focused on the role of radio in fostering economic empowerment for rural women in Ibeju Lekki, Lagos, the choice of radio stations and personnels to interview was narrowed to radio houses within Lekki, Victoria Island and Ikoyi precinct with and interest in family, business, women, career growth, nation, lifestyle and culture. This was done in a bid to narrow down the research focus to executable targets and also to understand (if any), ways through which radio stations within these vicinities have contributed to society, executed their corporate social responsibilities or social investments as regards the case of Rural women in Ibeju Lekki, Lagos.

To ensure that enough data was captured using a structured approach, the interview questions adopted an open ended style as advised by Kvale and Brinkman (2008). To ensure that information garnered for this research met validity and reliability standards, personnels contacted and recruited for the interview were administrative staff of these radio stations - COOL FM, WAZOBIA, INSPIRATION FM and FRCN. Additionally, Patton's (1991) advice that admonished researcher's using a structured interview approach to stick to a schedule and to lay out questions in a sequential order was followed as questions were designed, pre-planned and laid out in readiness for respondents. Additionally, the interview questions were sent to respondents through SMS and Whatsapp text messaging service two (2) weeks before proper interview and follow ups that occurred daily between $7 \mathrm{am}-9 \mathrm{am}$ and $6 \mathrm{pm}-9 \mathrm{pm}$. This was done to ensure that respondents had time to source for valid and testable answers to interview questions. The pattern was also followed for flexibility reasons being that some respondents had complained of lack of time and inability to type long texts or sit through lengthy call sessions. With a considerate amount of consistency and adherence to respondent's convenience, tangible data was garnered for this research. For this paper, data was obtained through three key avenues - through Whatsapp, SMS and phone calls. After the interview and data collection phase, the research utilized colour coding in highlighting relevant details needed for the purpose of this paper.

The radio stations selected for this study include INSPIRATION FM, WAZOBIA FM, FRCN and COOL FM.

\section{Rationale for Choice of Research Approach - Qualitative (Structured Interview)}

This research paper adopted the qualitative research approach to investigate the role of radio in fostering economic empowerment of rural women in Ibeju-Lekki, Lagos. The choice was based on the understanding that these qualitative approaches are known to mine rich and in-depth qualitative data from chosen respondents (Gray, 2014). This view synced with the researcher's vision because the researcher was interested in assessing and analysing qualitative data mined from administrative staff of selected radio stations as an approach to assessing the role of radio in fostering economic empowerment of rural women in Ibeju-Lekki, Lagos. It also synchronized with the plan towards researching radio's empowerment impact on women. Accordingly, the qualitative approach was also adopted to aid the researcher understand and see things from the respondent's perspective (Rubin \& Rubin, 2005).

\section{Methodology and Sample Size Selection for Bogije Women in Ibeju Lekki}

For the second part of this paper which is aimed at understanding the emerging and observed disconnect between radio and its ability to properly empower Bogije women of Ibeju-Lekki, women based in Bogije within Bogije road side Market Vacinity in Ibeju-Lekki were interviewed. Women who participated ranged in age between 2850. The residence status (living in Bogije) of these women were also confirmed as a fundamental prerequisite for participation in the research. A population size of 50 women was arrived at during the time of research. For the interviews conducted, the sample size of this research (44) was arrived at using the Taro Yamane formula with $95 \%$ confidence level (Yamane, 1967). The calculation is presented as follows;

$$
\mathrm{N}
$$

$\mathrm{n}=$

$$
1+\mathrm{N}(\mathrm{e})^{2}
$$


Where $\mathrm{n}=$ sample size required

$\mathrm{N}=$ number of people in the population

$\mathrm{e}=$ allowable error $(\%)$

Using the market population of women $=50$ and allowable error of $0.05 \%$

$$
\begin{aligned}
& \mathrm{n}=\frac{50}{1+50(0.05)^{2}} \\
& \mathrm{n}=\frac{50}{1+50(0.0025)} \\
& \mathrm{n}=\frac{50}{1+0.125} \\
& \mathrm{n}=\frac{50}{1.125} \mathrm{n}=44
\end{aligned}
$$

Furthermore, to assess radio's impact on women's economic empowerment in Ibeju-Lekki, this study adopted a qualitative approach similar to Somolu's (2013) study where he utilized a focus group approach to investigate women's use of radio and radio's impact on some women based in Lagos State. A similar approach was adopted instead of a quantitative approach that utilizes questionnaires in a survey. This approach was proficient because the sample population was feared to be largely made up of uneducated or half educated women who may have little or no prior knowledge of answering questionnaires. Owing to these perspectives, the approach chosen became the most favoured, concrete and tenable approach. Key guidelines proposed by Rubin and Rubin (2005) were followed - Considerations ranging from speaking the language of the respondents (Pidgin English) - in some instances to eliminate tension and foster trust, regulating the discussion to ensure one voice does not overwhelm the exercise and become the opinion of others to ensuring that leading and double barrelled questions were avoided. For this research, note taking was deployed for data capturing as respondents vehemently opposed voice recording. To ensure that relevant information was recorded, the researcher only picked points and perceived answers to the questions posed for coding and analysis. Additionally, manual colour coding was adopted to further assist in proper result filtration and its eventual display.

\section{Results}

Angle One - Radio's Role In Fostering Economic Empowerment for Women In

Ibeju-Lekki. - (Interview Questions and Answers)

1. What are the types and titles of programmes you air (broadcast) geared towards economic development and empowerment of women?

FRCN: radio 1, Women affairs discusses everything about women - health, finance, justice for women, etc. ... FRCN network: Kampe woman every Sunday $7 \mathrm{pm}$ discusses women in general. I doubt if the thrust is financial empowerment. ...From our discussions with our reps, Kaduna \& Kapital FM don't have women programs, others have but we can't measure the level of impact on the assumed women listening... If the thrust is financial empowerment for women, I don't think we have a dedicated women program of that sort.

WAZOBIA FM: materials from our Oga Madamme Office Show and some on Oyoyo show may be of interest to you.

COOL FM: Daddy Freeze and June Ubi had dealt extensively on financial opportunities for women. We have been working towards revamping programmes like that on our station.

INSPIRATION FM: A lot of our programmes revolve around women and the family... we also cover anything on economic empowerment with sharing life issues with Rufai Oseni. we tell our listeners about learning hard skills, job opportunities, and avenues to collect soft loans to start or continue to grow businesses. We also cover some of these issues on our Nite time shows even during our afternoon slots.

2. Are there any specific programmes aimed at economic empowerment of women (especially rural women in Ibeju Lekki)?

FRCN: ...If the thrust is financial empowerment for women, I don't think we have a dedicated women program of that sort... This boils down to sponsors. It is amazing to see the increase in the amount of female and gender programming especially online while terrestrial radio yearns for sponsors. We had hoped as stakeholders that 
companies through their corporate affairs unit will invest in sponsorship of such programming but alas. Sadly, this tends to correlate with high levels of under development...

WAZOBIA FM: ...none I can think of but the Oyoyo Show, Oga Madamme Office Show and Weekend Jollification Show is always jam packed with things on women. If you listen to these programmes regularly, you may have observed that we go beyond comedy and use Pidgin English to address society's challenges. Uche Smith popularly known as (Cheche) who sometimes anchors the Oga Madamme Office show is into tailoring and fashion... She drops a few tips here and there on her show to inspire women to go into fashion and textile business.

INSPIRATION FM: We do not have a clear cut programme for that but our umbrella shows contain a fusion of some of your concerns in that we do broadcast opportunities, teach skills and discuss DIY approaches to starting SME businesses. Our programmes also provide tips and clear hints on job openings and local, state or national opportunities where business people can pitch business ideas and get investors. On some occasions, we have invited key government dignitaries to the studio to be interviewed... more often than not they share information on how to access government or NGO support...

COOL FM: ...I can't point to anyone right now but I know our OAPs are neither biased nor deaf to trending social issues like this... they do talk about development and empowerment of women.

3. What are the focus points of these programmes?

FRCN:... for the few ones generally aimed at women, what we do is to invite women guests to speak on topical issues... FRCN also works closely with the state and federal government to broadcast opportunities to women through news items, programmes and press releases which could come in form of legal aid for domestic abuse, Health nuggets, women's right discussions, information and life hacks during interviews, advertisements placed by a specific Ministry and things like that. We also inform women on programmes out there where NGOs also partner with government to eradicate poverty and give as much helping hand as they can to natives to jump on their support programmes... (Interviewer - what types of programmes?) Yes, entrepreneurial programmes, skills acquisition and lecture series to help them take their business serious and make it profitable as well.... Something of that nature ... Before I forget, we also educate women through radio drama...

WAZOBIA FM: ...fashion and beauty, interview with Doctors on women's health, Skills Acquisition, how and where to get financial support, Information on how and where to get loan, relief materials like fertilizer, poultry farm equipment and other things; seminar and training on how to profitably execute a business.

INSPIRATION FM: ...Let me see, mostly we have talk shows and interviews and that is where you will potentially stumble on anything economic empowerment for rural women. The gist can revolve around business maybe FCMG retail or wholesale supplies, agriculture, investment in future generation through child education, knowledge procurement, tips on best practices, information on where to get loans and awareness on planned visits of an agricultural extension worker visiting a community to advise them on how to grow their produce.

COOL FM: The bulk of our abilities lie in Music and a little on the few chit chat sessions we have on our line up. Music plays a key role in persuasion and mood changes... So we speak through music, we also have professionals who occasionally come in to address our listeners on apprenticeship as a sustainable way to grow a strong work force; they also handle topics on personal and business development. Health and stress management, growth hacks in business and a lot of other topics that is important to Nigerians.

\section{How does your station know that these programmes have an impact on rural women in Ibeju Lekki?} FRCN:.... But we can't measure the level of impact on the assumed women listening.

WAZOBIA FM: At Wazobia FM, we frequently communicate with Pidgin English and most Lagosians are fluent with that... call frequencies coming from that area is often high - that is how we get to know that we have followers there practising what we preach.

INSPIRATION FM: They call in to ask questions, appreciate our guest or query them when their talk doesn't sit well with reality... one sent yams to Nonso one of our guest OAPs for speaking his mind...

COOL FM: When people call and eventually identify themselves our host, analyst and engineers behind the deck are equipped with state of the art gadgets to monitor calls and record conversations... being the director of programmes, I can tell you that we usually get a relatively moderate number of female callers from Ibeju Lekki very little of those calls come from women

4a. Are there feasible results to demonstrate the impact of these programmes

FRCN: Null

WAZOBIA FM: Our listeners attest to the potency of the advice we sometimes give and the information we gladly share. ... During our yearly outreach, we do meet some participants who benefitted one time or the other from calls to our guests for information on how to access support or for let's say loans. ...during the cancer awareness week, we met a lot of women who discussed how they used motivational stories and links to support that we shared to successfully grow their businesses to a point where they were able to comfortably fend for their families.

INSPIRATION FM: .... We take stock of the call in rates and listener engagement with programmes as well as 
OAP performances to keep up with the management of the station. Sometimes we purposely record calls to study listener's areas of concern and to help us create relevant content in future; aside calls and check-ups, we do meet up with some of the beneficiaries and callers on our annual praise jam outreach. We had an open air outreach in Lekki Ibeju in December 2017. There, we met some of our listeners who were also there to meet with their sponsors and to discuss progress reports and other things.

COOL FM: Null

5. Are there any other methods your radio station has adopted to reach out to rural women especially those in Lekki, Ibeju?

FRCN: Aside news, drama, interviews and the other ones I mentioned earlier, I'm not certain about other avenues. ...maybe our branch stations are impacting them in other ways...

WAZOBIA FM: Advertisements of products and services that can help women in their journey to economic independence, we have also partnered with our sister station Inspiration FM a couple of times on eventful dates to be of service to society. We are also planning to get across to women through children on Children's day. ...We operate an open door policy so listeners engage with us and share problems when we are in the field or during our awareness campaigns.

INSPIRATION FM: ...Partnership with NGOs, Churches, Agriculture and Microfinance Banks and other sectors of the economy to help women maximise their potential.

COOL FM: ...Let me get back to you on this (Stopped picking calls and returning messages).

Angle 2: RESEARCH AT BOGIJE, LEKKI IBEJU - Assessing the Impact of Radio's Economic Empowerment Efforts on Women of Bogije in Ibeju- Lekki.

Interview Questions and Answers on Radio's Reach, Content and Audience Interest.

SETTING 1: SALOON WITHIN BOGIJE ROAD SIDE MARKET - 10 WOMEN

Are you resident in Ibeju Lekki? - ALL SAID YES.

Do you listen to radio?

Woman 1: Yes I listen to radio Woman 2: that one na question? Woman 3: I dey listen radio sometimes Woman 4: I rarely listen to radio Woman 5: Very well Woman 6: Yes Woman 7: No I don't... Woman 8: Sometimes Woman 9: ...I prefer telemundo Woman 10: Yes na very well

Why don't you listen to radio -

Woman 7: Radio does not appeal to me. It is not trendy Woman 9: I prefer to watch

What stations do you listen to?

Woman 1: it depends on my mood and the songs I hear when I am scanning Woman 2: ...na wazobia and inspiration me I like Woman 3: mostly smooth fm and cool fm Woman 4: - Woman 5: Wazobia, Inspiration and cool fm Woman 6: I like wazobia and Inspiration Woman 7: ... Woman 8: Kiss and wazobia because they are always lively. Woman 9: I don't really like radio Woman 10: Brilla FM, Wazobia, Metro FM, Inspiration FM, mention am... any one wey sweet me for body na ih I dey listen.

How often do you get to listen to radio in Bogije

Woman 1: Not often. Business gets in the way Woman 2: I dey try but time no really dey to sidon like that Woman 3: I listen mostly when I'm driving Woman 4: ..... Woman 5: Very often... my husband is an ardent listener so i get to listen even when i don't want to because the volume is always loud Woman 6: Not often Woman 7: ... Woman 8: I tune in when I am bored Woman 9: Not often Woman 10: na regular thing

Do you understand the language used?

Woman 1: Yes Woman 2: Yes na Woman 3: very well Woman 4: Woman 5: nods affirmatively Woman 6: Yes Woman 7: Woman 8: Yes Woman 9: Woman 10: No be English? Who no understand English today...

How do you access these stations?

Woman 1: Battery Powered Radio and Phone Woman 2: Phone Woman 3: Car Radio and Phone Woman 4:... Woman 5: Home Theatre System, Battery Powered Radio and Phone Woman 6: Phone and Rechargeable lamp Woman 7:... Woman 8: Phone Woman 9:... Woman 10: Phone

Are there challenges you usually face while trying to access these radio stations?

None 


\section{Research Questions on Quality of Content and Listener's Interest}

Which radio station has helped you learn any skill you have used to make money?

Woman 1: I learnt bead making from wazobia before being trained Woman 2: ...the borehole business wey me and my husband start na from inspiration fm i take sabi... Woman 3: $\quad$ Woman 4: - Woman 5: Wazobia go always teach person how to make or cook something... Woman 6: I cannot remember which station maybe wazobia but radio taught me bulk garri, rice and beans business $\quad$ Woman 7: ... Woman 8: I import goods from china and sell them through our campus girls and online... and I learnt all that through radio - I have also collected soft loans from information I got from Kiss, Wazobia and Inspiration. Woman 9: Woman 10: I use number from radio call madam wey teach me to make hair... now I dey make follow sell original human hair.

\section{Which radio station has in any way provided information that helped you get or make money?}

Woman 1: Wazobia Woman 2: ...na wazobia ...Inspiration Woman 3: Woman 4: - Woman 5: Wazobia, Inspiration and cool fm Woman 6: Wazobia Woman 7: ... Woman 8: same here - Kiss, wazobia, inspiration and Brilla... Woman 9:... Woman 10: na Wazobia be am for me.

Can you recall the name/title of the programme?

Woman 1: no Woman 2: no Woman 3: no Woman 4: - Woman 5: no Woman 6: no Woman 7:... Woman 8:no. Woman 9: no Woman 10: no

Was the whole programme dedicated to training you on the skill?

Woman 1: yes the length of it for that day ...if I recall correctly it was a long talk about beads, Ankara and gele Woman 2: not at all... I just pick am up from list of businesses wey dem bin dey talk Woman 3: $\quad$ Woman 4: - Woman 5: Woman 6: No... they brought in a consultant to talk to women about dealing on farm produce. Woman 7: ... Woman 8 No... they spoke a bit on it and invited listeners to a paid training session that I went and it turned out good in the end. Woman 9: Woman 10: no

What did you learn from the programme?

Woman 1: beads making Woman 2: nothing aside the borehole business. $\quad$ Woman 3: Woman 4: Woman 5: catering business and how to prepare edikang ikong soup... Woman 6: bulk garri, rice and beans business Woman 7:... Woman 8: Importation business and how to get loan for it Woman 9: Woman 10: Hair making.

How were you able to apply the knowledge?

Woman 1: I run a production line where I make and sell beads $\quad$ Woman 2: $\quad$ Woman 3: $\quad$ Woman 4: Woman 5: I started a restaurant and I do outdoor catering Woman 6: I was motivated into starting the wholesale business Woman 7: ... Woman 8: Importation business and how to get loan for it Woman 9: Woman 10: Hair making.

\section{SETTING 2: MARKET STALLS- 20 WOMEN}

Interview Questions and Answers on Radio's Reach, Content and Audience Interest. Are you resident in Ibeju Lekki? - ALL SAID YES.

Do you listen to radio? - All Said No

Why don't you listen to radio -

Woman 1 - I don't have time Woman 2: It is not Interesting Woman 3: I don't have a radio... will you buy for me? Woman 4: I have not had any reason to listen to radio Woman 5: Radio is a waste of time - It is better to watch TV Woman 6: There is no time to listen to radio Woman 7: Radio is for lazy people Woman 8: I don't need radio... I have internet in my phone and tv in the house Woman 9: Radio is not interesting Woman 10: No reason Woman 11: No reason Woman 12: Its noisy and not entertaining Woman 13: I bin don tire to listen tey tey Woman 14: Nobody dey listen radio again na Woman 15: I no get radio... Woman 16: No reason Woman 17: I too dey busy Woman 18: my church does not permit that... Woman 19: it's the same thing... My church does not allow radio. Woman 20: No time.

SETTINGS - STALL VARENDAS - 15 WOMEN

Are you resident in Ibeju Lekki? - ALL SAID YES.

Do you listen to radio?

Woman 1: noo... e don tey wey I listen radio. Woman 2: no Woman 3: I dey listen when light dey or if I get 


battery for phone. Woman 4: very well. $\begin{aligned} & \text { Woman 5: no. } \\ & \text { Woman 9: no Woman 6: no. Woman 7: no }\end{aligned}$ Woman 8: no
no $\quad$ Woman 15: no

Why don't you listen to radio?

Woman 1: no money to buy radio Woman 2: I no like radio

Woman 5: wetin dem wan tell me again?

Woman 6: light no dey constant Woman 7: the tin dey tire me Woman 8: I no want am Woman 9: my husband no like radio Woman 10: them no get programmes wey I for like Woman 11: I don't know Woman 12: Nil Woman 13: Nil Woman 14: Nil Woman 15: I not like radio

\section{What Stations do you listen to?}

Woman 3: anyone wey dey play better gbedu... Cool FM dey try for music Kiss FM too then this oda one wey just open... Woman 4: Inspiration FM mostly

How often do you get to listen to radio in Bogije?

Woman 3: ...na here I dey live so na everyday matter Woman 4: ... No be everytime. Na when I fit naih I dey listen.

\section{Do you understand the language used?}

Woman 3: ... sometimes o Woman 4: ... I dey try

How do you access these stations?

Woman 3: ... I get phone, I get battery radio I follow get the one wey dey waka wit cd player Woman 4: ... Better sound system dey house

Are there challenges you usually face while trying to access these radio stations?

Woman 3: ... no challenge Woman 4: If light no dey, how person go take listen am?

\section{Research Questions on Quality of Content and Listener's Interest}

Which radio station has helped you learn any skill you have used to make money?

Woman 3: I no learn any skill from radio Woman 4: e no get any wey I take learn wetin I dey do for hand make e gimmi money.

Which radio station has in any way provided information that helped you get or make money? Woman 3: Nods sideways... None Woman 4: None

Can you recall the name/title of the programme?

Nil

Was the whole programme dedicated to training you on the skill?

Nil

What did you learn from the programme?

Nil

How were you able to apply the knowledge?

Nil

\section{Discussion and Recommendation}

The results above reflect outcomes of engagement with four radio station located within Ikoyi, Victoria Island and Lekki in Lagos State Nigeria. From our sojourn in the field and with representatives of these radio stations, there is an almost observable trend and similarity between operations and responses across the four chosen case studies. Radio has institutionalized its presence over time and from the data received from respondents, it is safe to say that radio is still one of the few relevant mass media platforms resonating with the masses. While there is however a perspective that posits that radio stations fleetingly tackle issues surrounding the economic empowerment of rural women within Lagos and with emphasis to women within Ibeju Lekki, a few observable keywords frequently used during interviews and discussion of radio's role in fostering economic empowerment for rural women may be of interest here as a means to further understand the role of radio in fostering economic empowerment of rural women as well as the agenda radio is consciously or unconsciously setting towards a certain perception of women in a social context.

From the data garnered from the result of the research, there may be more than two phases to the role these radio stations play in fostering or discouraging economic empowerment of rural women. First, the positives - 
From the points highlighted in the results, there is a considerable effort towards economically empowering women in general. These efforts although perceivably fleeting and inconsistent, ensure that women are either exposed to advertisements supporting economic empowerment of rural women or remain informed on job opportunities, opportunities to benefit from government or NGO support and grants, skills training over the radio, access to subsidized micro finance bank loans, tips to properly starting and growing businesses etc. According to the respondents, the emphasis takes various formats and are ingrained in programmes such as talk shows/interviews, radio drama, music, news, press releases etc. Furthermore, respondents from Inspiration FM and Wazobia FM (as highlighted in the result) have stressed being actively engaged in social activities geared towards economic empowerment of women. They have also observed positive impacts and strongly believe that the process will remain sustained through outreach and praise jam concerts/ festivals that engender interactions. Observably, one could say that these types of social activities and information aid the economic empowerment of women and equips them with the confidence to advance their lives and grow their finances and the economy. From this perspective, radio is playing its positive role in fostering economic empowerment for women. Furthermore, the four radio stations have to a certain extent emphasized needed information geared towards economically empowering rural women in Ibeju-Lekki and generally although audience and impact measurement appeared controversial. These laudable strides towards changing existing perspectives on the perception of women especially rural women in society may eventually peak at positive success points as it will advance the image perception of rural women by society and media as value creators and independent beings capable of creating, contributing and benefitting from tangible value created to grow self and the nation's economy. Consequently, radio could be said to be promoting a positive image of women through positive agenda setting. These positive strides ties with radio's efforts globally as highlighted in the literature review and backs Asemah's (2011) postulation on the use of radio by different entities to facilitate development and empowerment of people within societies.

On close assessment of the data and the underlying subtones embedded in the data describing efforts radio is exerting in economically empowering Ibeju- Lekki women, there are other perspectives that could possibly limit radio's effort towards catalysing economic empowerment for rural women. These perspectives are domiciled in the observation that there are no programmes on these four platforms specifically designed to keep rural women updated on opportunities geared towards economic empowerment of women. So, there is ideally no established time interval on these radio platforms where women are glued to the radio to pick up on opportunities shared on air. While this may be attributed to lack of sponsors or probable disinterest in the subject, it is important that this challenge be tackled to help radio play its proper role in fostering economic empowerment for rural women.

Secondly, there is a perspective on radio programme's focus that tends to place women as vulnerable and susceptible to stress, abuse or violence, hence the need for proper self-medication and management as well as orientation on rights and help lines to be reached in readiness for abuse or violation. This area of concentration also emphasizes other aspects of empowerment that a reader may have also observed from the literature analysed. These areas include emphasis on family/household, health, information, social, rights and educational empowerment for women sometimes exemplified in emphasis on war against violence and abuse aimed at women, freedom of access to information, legal advisors and human rights activist, use of contraceptives, fight against cancer, self-care and beauty tips etc. While these perspectives portray women along the lines of victims and fragile beings in need of help, radio's emphasis on other aspects of empowerment for women prioritizes other ramifications of empowerment and relegates the economic empowerment of women to fleeting seconds of discussions or adverts - in a way implying its irrelevance or inconsequential status. Additionally, the emphasis on other aspects of women empowerment limits radio's strides towards properly assuming a tangible and commendable role in fostering economic empowerment of rural women.

This understanding stems from the idea that on air time is expensive and precious; thus, women empowerment issues could be better designed and administered within the allotted time in a manner that neither consciously demean women nor unconsciously portray them within negative stereotypical lights. Also, attention or emphasis could be equally distributed across different facets of women empowerment discussions to ensure that one doesn't take pre-eminence over the other and used as a yardstick for grooming an understanding of women. In essence, economic empowerment of women is to a great extent as valuable as the attention placed on health and beauty. Thus, time allocated for discussion for different facets of empowerment could be equally shared to reflect on the value and relevance accorded strides towards fostering economic empowerment of women as another important branch of women empowerment worth its onion on air.

Additionally, from a strategic communication perspective aimed at empowering women, the types of portrayals and emphasis on issues bothering on abuse and violence on women, stress management and selfmedication over the radio does not help the case of a positive image perception of women by society which is media in itself. Thus, while this may or may not be an oversight, it does impact on the agenda radio is setting towards the perception of women in that it re-emphasizes existing perceptions about women/ rural women in line 
with being weak and defenceless i.e. overshadowed by hardship and atrocities inflicted on them (Narayana \& Ahamad, 2016), less fit within industrial and business settings (Wood, 2012).etc. For this to go away, radio as a social institution must adopt proper strategic communication approaches in encouraging and communicating economic empowerment of women to society - either through advertisement, during interviews, radio drama and other aspects and mediums it chooses to inform, advertise or appeal to other women and people in the society.

From an impact angle, the data presented suggests that a certain quota of the sample study group have benefited from radio's effort towards economically empowering women. The result reflects that women in Bogije in Ibeju-Lekki receive signals from the four radio stations selected for this study. Furthermore, it does highlight the perspective earlier noted that there is no programme on these platforms (COOL FM, INSPIRATION FM, WAZOBIA FM, FRCN ) base in Lagos, specifically designed to help women acquire skills and receive detailed information on business or avenues to access loans as a means to economically empower women. While language, content, reach and audience interest were initially fingered to be the cause of the disconnect between these radio station's inability to properly empower women economically, it turns out that language has contributed little to nothing in the way of obstructing radio's effort in delivering economic empowerment for women. As it relates to reach, while it was clear that radio signals permeated the entire length and breadth of the vicinity, most respondents were unable to access these signals because of either the inability to afford a radio set, disinterest in radio and inability to find or afford existing and fluctuating electricity source or battery to power radio sets for those who owned one. Aside the lack of content strategically positioned to inform women or train them over the radio; , results have also shown that a lot of women within the selected sample occasionally or do not listen to radio and have various reasons or ideologies backing these positions.

Some of these reasons include lack of time, the ideology that radio is a waste of time and also meant for lazy people, the view that radio is not trendy, lack of funds and electricity to purchase and use radio, preference for TV and the internet, the feeling that radio is noisy and not entertaining, spouse's disinterest in radio being a reason behind dislike for radio, lack of interesting programmes to spark interest, ignorance/ cluelessness and interestingly the position that their church's doctrine does not permit it's members to listen to radio.

These views, on a closer look may be the primary reason for radio's inability to economically empower women in Nigeria - Bogije Ibeju Lekki. The culture of listening or listenership can be said to be degenerating as has been observed in the results. While findings in this paper already supports the agenda settings theory, this current position on why rural women in Bogije listen or do not listen to radio further affirms the potency of the theory of uses and gratification which posits that people have reasons why they use media or expose themselves to certain content - where value is not received; people tend to avoid engagement with these types or forms of media (Asemah, 2011). The findings further cement the uses and gratifications theory in that it backs the ideology that despite the research finding's tilt, there are segmented individuals in Bogije in Ibeju Lekki with a flair for listening to radio. Similarly, the results appeal to another media audience theory which is the reception theory which posits that contents are neutral in meaning and mean different things to different people on arrival (Asemah, 2011). Hence, an agenda setting which in some ways emphasizes the function of media can only hold when individuals are consciously exposed to content and are cognitively willing to engage media and its content.

Furthermore, while there is need for radio to rework it's economic empowerment content geared towards women and society, there is need to balance this effort with an appreciation in number of consistent listeners in a day and age where numerous media and content compete for an individual's attention. To further enable radio play a significant role in fostering economic empowerment for women in Ibeju-lekki, key focus areas in need of attention would be the revitalization of listenership culture and strict attention to design and strategic scheduling or placement of radio content aimed at economically empowering Ibeju-Lekki women. In line with the focus of economic empowerment for this paper - women could be trained on key skills over the radio, coached on best business models/ approaches and furnished with information on best avenues to access loans.

\section{Conclusion}

This paper assessed the role of radio in fostering economic empowerment of rural women in Bogije Ibeju-Lekki. Using four radio stations as case studies, the paper arrived at an understanding that these stations are fleetingly contributing positively to catalysing economic empowerment of rural women in Ibeju-Lekki through information sharing and dissemination that has helped women access subsidized loans, trained women on soft and hard skills over the radio, offered tips and encouragement amidst other physical efforts geared towards financially empowering women and rural women in Ibeju Lekki Specifically. Additionally, there is a perspective that admonishes media professionals and those in control of radio to monitor their communication style and how they present women and issues surrounding women in order to aid the growth of a positive image perception of women by media and society. This view is also supported by recommendations proposing that issues surrounding economic empowerment of rural women be given equal preference with other women empowerment discussions on radio platforms to aid a balanced view and perception of positive strides by media aimed towards empowering women and shifting society's traditional perception of women away from existing 
paradigms into fresh and just perceptions. Consecutively, the research findings from the audience angle of the research (Bogije women In Ibeju-Lekki) projects that audience have been segmented and interests have shifted with relation to medium and content of medium. Hence, for radio to play a proper role in fostering economic empowerment in Ibeju Lekki, there is need for proper content design and delivery as well as stringent remarketing to boost listenership, sew the dying link between radio and women of Bogije and aid in proper skills development and information provision broadcasted and utilized by a majority of rural women in Bogije in Ibeju-Lekki.

\section{References}

Akhter, N and Naheed, F. (2014). Perceptions of Educated Women about the Role.of Media in Women Empowerment. European Scientific Journal November 2014 edition vol.10, No.31 ISSN: 1857 - 7881 (Print) e - ISSN 1857- 7431280

Asemah, E. (2011). Selected Mass Media Themes. Jos, Jos University Press.

Asemah, E. (2011). Mass Media in the Contemporary Society. Jos, Jos University Press.

Devi, L. (2012). Empowering Women through Alternative Media. Available at: https://www.rtc.bt/Conference/2012_10_15/2-MeenaLongjam-AlternativeMedia.pdf (Accessed 18th May, 2018)

Elutidoye, G. (2017). What is Nigeria's History of Radio Broadcasting?. Available at: http://www.quora.com/what-is-Nigerias-history-of-radio-broadcasting (Accessed 29th May, 2018)

Gupta, S. (2018). A Study on Role of Media in Women Empowerment in India. International Journal of Advance Research, Ideas and Innovations in Technology, 4(1). Available at: https://www.ijariit.com/manuscripts/v4i1/V4I1-1188.pdf?a4c545\&a4c545 (Accessed, 7th May, 2018)

Gray, D. (2014). Doing Research in the Real World (3rd Edition). London: Sage Publications Limited.

Hyginus, A. and Kennedy, O. (2017). A Focus On Campaigning For women empowerment through radio programming in Niger state. International Journal of Social \& Management Sciences, Madonna University (IJSMS) Vol.1 No.1, March 2017; pg.67 - 83. Available at: file://C:/Users/Amindi-Abasi/Downloads/189706-1-PB.pdf (Accessed 20th May, 2018)

Kwaramba, A. \& Morna, C. (2003). Gender and Media Baseline Study, Tanzania Report. Johannesburg: Media Institute of Southern Africa (MISA) and GenderLinks (GL). Available at genderlinks.org.za/what-wedo/media/research/gender-and-media-baseline-study/ (Accessed 4th April 2018)

Kvale and Brinkman (2008). Interviews. 2nd Edition. Thousand Oaks: Sage.

Lantagne, A. (2014). Gender Roles in Media. Available at https://www.huffingtonpost.com/allisonlantagne/gender-roles-media b 5326199.html (Accessed 2nd April 2018)

Mali, N. \& Patankar, P. (2015). Role of Media In Prohibition Of Gender Discrimination. Research Front. I. 5156.

Available

at https://www.researchgate.net/publication/286156021_ROLE_OF_MEDIA_IN_PROHIBITION_OF_GEN DER DISCRIMINATION (Accessed 3rd April 2018).

Moghadam, V. (2007). From Patriarchy to Empowerment: Women's Participation, Movements And Rights in the Middle East, North Africa, and South Asia. New york: Syracuse University Press.

Morna, C \& Mufune, A. (2005). Media on the a - Gender. Audit of the Southern Africa: Declaration on Gender and Development. Johannesburg: DS Media.

Morna, C. (2002). Promoting Gender Equality In and Through the Media: A Southern African Case Study. Available at http://www.un.org/womenwatch/daw/egm/media2002/reports/EP5Morna.PDF (Accessed 3rd April 2018)

Musubika, J. (2008) Community media and the empowerment of rural women in Uganda: a study of Mama Fm Radio. Available at: https://www.duo.uio.no/bitstream/handle/10852/27710/Musubika.pdf?sequence=2

(Accessed 6th May, 2018)

Narayana, A. \& Ahamad, T. (2016). Role of media in accelerating women empowerment. International Journal of Advanced Education and Research. 1. 2455-5746.Available at: https://www.researchgate.net/publication/303998838_Role_of_media_in_accelerating_women_empowerm ent (Accessed 10th May, 2018)

Nirmala, Y. (2015). The role of community radio in empowering women in India, Media Asia, 42:1-2, 41-46, DOI: $\quad 10.1080 / 01296612.2015 .1072335 \quad$ Available at: https://www.tandfonline.com/doi/pdf/10.1080/01296612.2015.1072335?needAccess=true (Accessed 20th May, 2018)

OEDC. (2018). Women's Economic Empowerment. Available at: http://www.oecd.org/dac/genderdevelopment/womenseconomicempowerment.htm (Accessed 20th May 2018)

Obiunu, J. (2013). The Effect of Gender Sensitivity On Discrimination Among Secondary School Students. Journal of Emerging Trends in Educational Research and Policy Studies (JETERAPS) 4(6): 888-894. 
Available at Jeteraps.scholarlinkresearch.org (Accessed 4th April 2018)

Patton (1991). Qualitative Research \& Evaluation Methods, 3rd Edition. Thousand Oaks: Sage. ISBN 978-07619-1971-1

Potter, J. (2014). Patterns in the use of theory in Media Effects Research. In Fortner, R and Mass

Ray, A. (2009). Impact analysis of Mandeshi Tarang, the community radio of Mhaswad. Available at https://www.globalgiving.org/pfil/2151/projdoc.doc\%2BImpact+ analysis + of + Mandeshi + Tarang + community + radio + of + Mhaswad $\& g b v=1 \& \& c t=c l n k$ (Accessed 10 th May, 2018)

Rubin, H. \& Rubin, I. (2005). Qualitative Interviewing: The Art of Learning Data. California: Sage Publishers.

Somolu, O. (2013). Radio for Women's Development: Examining the Relationship between Access and Impact. Women's Technology Empowerment Centre (WTEC). Nokoko Institute of African Studies Carleton University (Ottawa, Canada) 2013 (3)

The Tide. (2016). Mass Media And Women Empowerment. Available at http://www.thetidenewsonline.com/2016/04/08/masss-media-and-women-empowerment/ (Accessed 12th May, 2018)

Wimmer, R. \& Dominick, J. (2006). Mass Media Research: An Introduction. (8th ed). Belmont, CA: Thomson and Wadsworth.

Wood, J. (2012). Gendered Media: The Influence of Media on Views of Gender. Available at https://www.nyu.edu/classes/jackson/causes.of.gender.inequality/Readings/Wood\%20\%20Gendered\%20Media\%20-\%2094.pdf (Accessed 3rd April 2018)

Yalala N. (2015). The Role of Community Radio in Empowering Women in India. J Mass Communication Journalism 5: 245. doi:10.4172/2165-7912.1000245 ISSN: 2165-7912 JMCJ

Yamane, T. (1967). Statistics: An Introductory Analysis, 2nd Edition. New York: Harper and Row Publishers. 